\title{
Desenvolvimento osteológico de Hippocampus reidi Ginsburg (Pisces, Syngnathiformes, Syngnathidae), em laboratório. II. Período juvenil
}

\author{
Rosana Beatriz Silveira ${ }^{1,2}$
}

\begin{abstract}
Osteologic development of Hippocampus reidi Ginsburg (Pisces, Syngnathiformes, Syngnathidae), under laboratory conditions. II. Juvenile phase. The sequence of events of the ossification process in the newly born specimens of Hippocampus reidi Ginsburg, 1933 up to 37 days of life has been described, mainly the ossification in the ethmoid plate, palatine, pectoral girdle, and postorbital bones and bony structures such as mesoethmoid, articular and six suborbitals. Observation on adult specimens are presented too.
\end{abstract}

KEY WORDS. Hippocampus, seahorse, osteology

Poucos são os trabalhos realizados com cavalos marinhos. No Brasil, à exceção do Projeto Hippocampus (SILVEIRA 1998a,b, 1999), inexistem publicações a respeito destes peixes, e no mundo, poucos são os pesquisadores que, com expressão, estudam este tema, destacando-se VINCENT (1992, 1994a,b, 1995), VINCENT et al. (1992), VINCENT \& SADLER (1995), entre outros. O presente artigo descreve o desenvolvimento ósseo de Hippocampus reidi Ginsburg, 1933 na fase juvenil, do recém-nascido até 37 dias de vida e é complemento seqüencial de SILVEIRA (2000) que descreve o desenvolvimento ósseo na fase embrionária.

\section{MATERIAL E MÉTODOS}

Os espécimes foram provenientes da Barra de São Miguel, Maceió, AL, Brasil. Os animais foram mantidos em quarentena e receberam tratamento profilático com $\mathrm{CuSO}_{4}$ (sulfato de cobre, solução estoque a $1 \%$ ), na diluição de $0,5 \mathrm{ml}$ da solução estoque para cada litro de água do aquário. A alimentação dos reprodutores constou de espécimes adultos de Artemia sp. (Crustacea, Anostraca), cultivados em laboratório e oferecidos três vezes ao dia. Após o período de quarentena e concluídos os exames de pele e fezes, que constituem rotina em piscicultura, foram selecionados espécimes com o seguinte aspecto: boa coloração, o que consiste num padrão uniforme, sem manchas assimétricas, pálidas ou escurecidas; movimentos natatórios regulares na intenção de caçar ou investigar uma possível presa; quando em posição de descanso, cauda enrolada em alguma superfície e bom apetite. Este item pode levar mais de um mês para se manifestar, pois alguns indivíduos levam mais

1) Laboratório de Aqüicultura Marinha. Avenida Delmar Rocha Barbosa 563, Parque Santa Fé, 91180-490 Porto Alegre, Rio Grande do Sul, Brasil. E-mail: labaquac@yahoo.com

2) Departamento de Zoologia, Instituto de Biociências, Universidade Federal do Rio Grande do Sul. Avenida Paulo Gama, Prédio 12105, 90040-600 Porto Alegre, Rio Grande do Sul, Brasil. 
tempo para aclimatarem-se a esta nova vida, em cativeiro. Por este motivo, todos os aspectos citados devem ser avaliados conjuntamente. Ao término da seleção, foram colocados em aquário comunitário para formação dos casais (escolha feita entre os próprios peixes). Após, separados novamente, conforme tal escolha, para acasalamento.

O primeiro acasalamento ocorreu em temperatura de $25 \pm 1^{\circ} \mathrm{C}$, densidade variando entre 1020 e 1022 e fotoperíodo de 12L:12E. Os níveis de amônia, nitrito, nitrato e $\mathrm{pH}$ foram monitorados com kits para medições em aquários marinhos $\mathrm{e}$ seguiram BROWNELL (1980a,b). Os trabalhos concentraram-se neste primeiro casal. A incubação dos ovos, pelo macho, durou 21 dias. Ao nascimento, contou-se uma prole de 502 alevinos, dos quais 250 espécimes foram cultivados, observando cinco espécimes por litro.

A técnica de diafanização, a terminologia adotada para os estágios do desenvolvimento, bem como a terminologia osteológica está citada em SILVEIRA (2000).

Os espécimes diafanizados totalizaram 74 indivíduos nas seguintes idades: recém-nascidos ( 10 espécimes), 3 dias de vida (dv, 10 espécimes), $7 \mathrm{dv}$ (5 espécimes), $10 \mathrm{dv}$ ( 2 espécimes), $16 \mathrm{dv}$ (3 espécimes), $20 \mathrm{dv}$ (8 espécimes), $25 \mathrm{dv}$ (8 espécimes), $30 \mathrm{dv}$ (10 espécimes), $37 \mathrm{dv}$ (8 espécimes) e 10 espécimes adultos. $\mathrm{O}$ comprimento total (CT, do ápice da cabeça à extremidade da cauda) dos espécimes foi medido em ocular de medição e com paquímetro.

Os espécimes analisados estão retidos junto ao autor.

\section{RESULTADOS}

\section{Recém-nascido}

Nesta fase, os juvenis apresentam média de $6,36 \mathrm{~mm}$ de CT. Com a placa etmóide em um plano linear (Fig. 3), sem a curvatura presente no embrião (Fig. 2), o focinho alongado suporta, em sua porção distal, as maxilas, palatino, quadrado, ectopterigóide e cartilagem rostral (Figs 1, 3). O pré-maxilar e maxilar, estruturas pares, de ossificação intramembranosa, colocam-se de cada lado, a partir da cartilagem rostral em direção ao dentário. Nenhum destes elementos possuem dentes (Fig. 3). Os palatinos, ainda cartilaginosos, são estruturas muito evidentes pelo seu tamanho, projetam-se da cartilagem rostral em direção ao quadrado, colocando-se na face dorsal do ectopterigóide dermal. A cartilagem de Meckel encontra-se envolvida pelo dentário, este de origem dérmica (Figs 1, 3). O angular posiciona-se na face posterior da cartilagem de Meckel e o retroarticular na face póstero-lateral da mesma, o primeiro como ossificação endocondral e o segundo como intramembranosa (Fig. 1). O articular coloca-se em posição póstero-lateral ao angular. O supra-etmóide apresenta-se como uma fraca ossificação dérmica (Fig. 4). A placa etmóide é cartilaginosa e as placas ectemóides, também cartilaginosas, fusionam-se para formar o arco ectemóide que se lança para dentro, entre as cápsulas ópticas (Fig. 4). Na região olfatória, na altura do arco ectemóide, está o pré-frontal, ainda cartilaginoso (Fig. 4) e o etmóide lateral. Não observamos o vômer, mas está se modelando uma longa e fina estrutura que vai da região anterior da cartilagem rostral até os pré-frontais, constituindo-se no mesetmóide. 


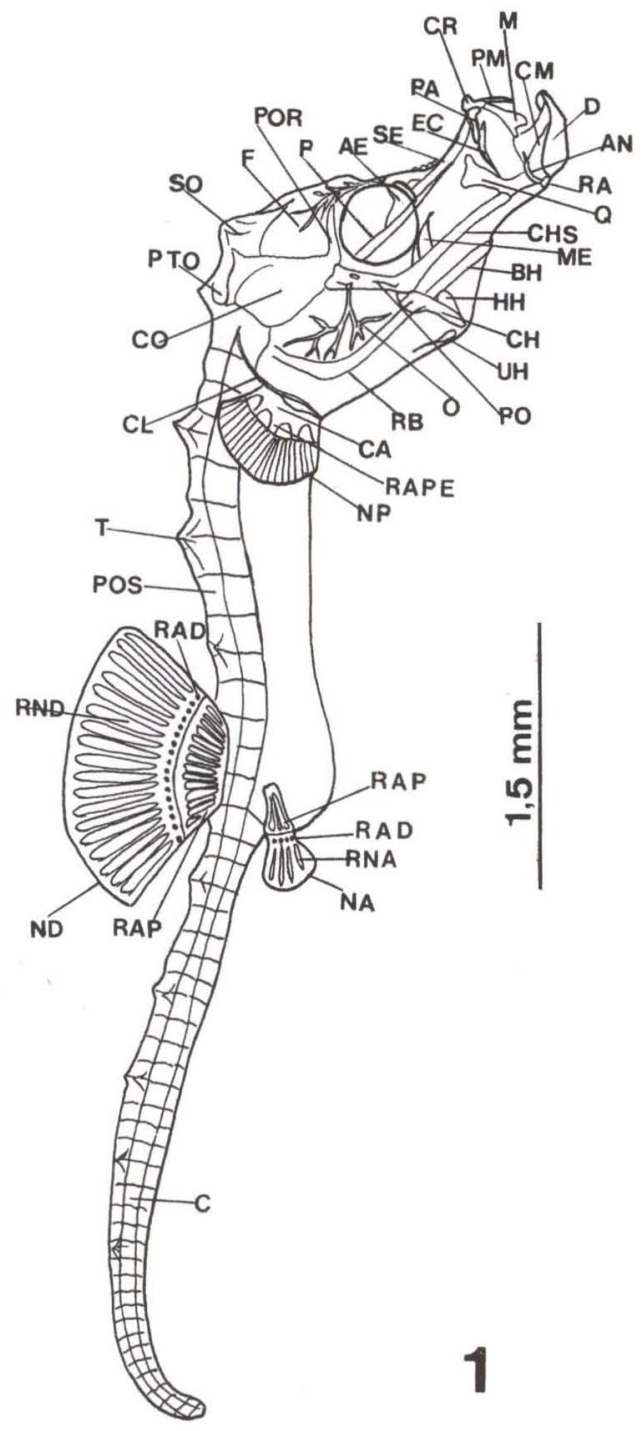

Fig. 1. Hippocampus reidi, um dia de vida. (AE) Arco ectemóide, (AN) angular, (AR) articular, $(\mathrm{BH})$ basi-hial, $(\mathrm{C})$ cauda, $(\mathrm{CA})$ coracóide, $(\mathrm{CH})$ cerato-hial, (CHS) cartilagem hiosimplética, (CL) cleitro, (CM) cartilagem de Meckel, (CO) cápsula ótica, (CR) cartilagem rostral, (D) dentário, (EC) ectopterigóide, (EN) endopterigóide, (EP) epiótico, (ES) esfenótico, (F) frontal, (HH) hipo-hial, (IH) inter-hial, (M) maxilar, (ME) metapterigóide, (NA) nadadeira anal, (ND) nadadeira dorsal, (NP) nadadeira peitoral, $(O)$ opérculo, $(P)$ paresfenóide, $(P A)$ palatino, $(P E)$ placa etmóide, (PM) pré-maxilar, (PO) pré-opérculo, (POR) pós-orbital, (POS) placa óssea, (PTO) pterótico, $(Q)$ quadrado, $(R A)$ retroarticular, (RAD) radial distal, (RAM) radial mesial, (RAP) radial proximal, (RAPE) radiais peitorais, $(R B)$ raios branquiostegais, (RNA) raio da nadadeira anal, (RND) raio da nadadeira dorsal, (S) simplético, (SE) supra-etmóide, (SO) supra-occipital, $(\mathrm{T})$ tubérculo, $(\mathrm{UH})$ uro-hial. 


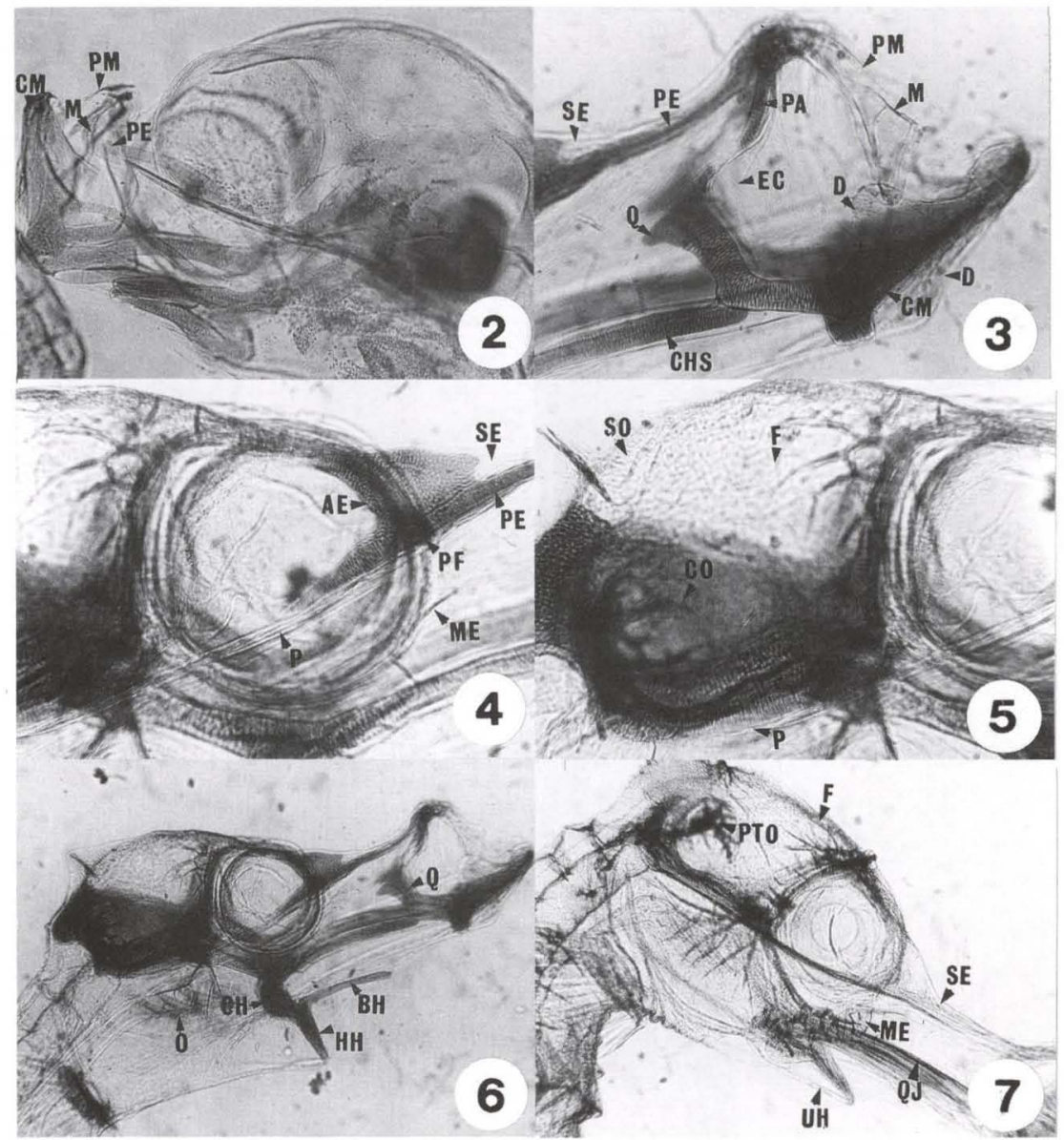

Figs 2-7. Hippocampus reidi, desenvolvimento de embrião até sete dias de vida. (2) Sincrânio embrião; (3) região oromandibular com um dia de vida; (4) região orbital com um dia de vida; (5) neurocrânio lateral com um dia de vida; (6) sincrânio com um dia de vida; (7) sincrânio com sete dias de vida. (AE) Arco ectemóide, $(\mathrm{BH})$ basi-hial, $(\mathrm{CH})$ cerato-hial, $(\mathrm{CHS})$ cartilagem hiosimplética, (CM) cartilagem de Meckel, (CO) cápsula ótica, (D) dentário, (EC) ectopterigóide, (F) frontal, $(\mathrm{HH})$ hipo-hial, $(\mathrm{M})$ maxilar, $(\mathrm{ME})$ metapterigóide, $(\mathrm{O})$ opérculo, $(\mathrm{P})$ parasfenóide, (PA) palatino, (PE) placa etmóide, (PF) pré-frontal, (PM) pré-maxilar, (PTO) pterótico, (Q) quadrado, (QJ) quadradojugal, (SE) supra-etmóide, (SO) supra-occipital, (UH) uro-hial.

O metapterigóide dermal encosta sua face dorsal na cápsula óptica (Fig. 4), continuando seu crescimento na direção do quadrado, porém apresentam-se bastante distantes um do outro. O quadradojugal, osso dérmico, cresce, inicialmente, sobre o lado dorsal do simplético; este último encontra-se em ossificação endocondral.

O paresfenóide é um osso dérmico, indo do basioccipital até a região dorsal do quadrado, ventralmente à placa etmóide. (Figs 4, 5). O quadrado, ainda cartila- 
ginoso, coloca-se na região anterior do focinho tubular (Fig. 6) e sobre o qual, quase imperceptível, está o endopterigóide intramembranoso.

$\mathrm{O}$ arco hióide exibe os primeiros sinais de ossificação em suas peças pares, cerato-hiais, hipo-hiais e inter-hiais. O basi-hial está completamente cartilaginoso. $\mathrm{O}$ uro-hial é osso dermal, assim como os raios branquiostegais. O opérculo é osso dérmico e articula-se com a face látero-posterior do hiomandibular (Fig. 6). O pré-opérculo, de mesma origem, começa a ser formado a partir da parede lateral posterior do hiomandibular, posicionando-se em direção ao simplético. Tanto o opérculo como o pré-opérculo apresentam projeções ósseas em forma de cristas. Os arcos branquiais, em número de quatro, estão cartilaginosos.

O simplético e o hiomandibular formam uma peça única, em forma de um "L" invertido (Fig. 1). A face simplética, nesta fase, é ventral à extensão do quadradojugal, enquanto que a face hiomandibular, em sua porção dorsal, conecta o crânio.

As nadadeiras peitorais apresentam 15 raios não ossificados. A dorsal varia entre 17 e 18 raios, cujos radiais proximais, em número de 16, apresentam fusão entre $015^{\circ}$ e $16^{\circ}$ elementos. A nadadeira anal apresenta quatro raios cartilaginosos, quatro radiais distais e quatro proximais com fusão entre o $3^{\circ}$ e $4^{\circ}$. O cleitro, osso dermal, articula-se com a primeira vértebra, descendo obliquamente na altura da nadadeira peitoral e bifurcando-se, em ambos os lados, ventralmente. Os radiais da nadadeira peitoral, o coracóide e a escápula estão cartilaginosos e conectam na face ventral do cleitro. Crescem, por todo o corpo do animal, estruturas que designamos tubérculos ósseos; sobre a nadadeira dorsal aparecem três destes, de cada lado, inclusive na cauda, porém em tamanho menor (Fig. 1).

Nesta fase, a delicada coluna vertebral que se estende da região basicraniana até a placa hipural, no extremo da cauda, apresenta ossificação nas vértebras, a partir do atlas até a $32^{\circ}$ vértebra. Juntamente com as vértebras, dorsal e ventralmente, os arcos neurais e hemais, respectivamente, também ossificaram. Os anéis que constituem o exoesqueleto do juvenil ossificaram e na região ventral, ainda, estão fechando o corpo do animal.

No neurocrânio, o pós-temporal encontra-se cartilaginoso. A taenia tectum medialis é uma cartilagem ímpar, que se coloca entre os frontais e a porção anterior do supra-occipital. O frontal, osso dérmico, emite projeções ósseas, cristas, ocupando a região ântero-dorsal do crânio. O processo pós - orbital apresenta-se cartilaginoso. Há um inicio de ossificação no esfenótico que se articula látero-ventralmente por sincondrose com o hiomandibular, lateralmente com o pterótico e ventralmente com o pró-ótico. O pterótico articula-se por sincondrose com o epiótico. O epiótico, de cada lado do supra-occipital, sutura-se por sinostose a este, e por sincondrose ao exoccipital, osso que ocupa a maior parte da face póstero-ventral do crânio. O basioccipital ossificou, assim como o supra-occipital que apresenta cristas (Figs 5, $6)$.

Observa-se na região posterior do neurocrânio, ventralmente, o forame magno envolvido pelo exoccipital. Na região anterior, encontramos o pequeno forame trigeminal no pró-ótico e o forame para inserção da inervação do hiomandibular no esfenótico. 


\section{Sete dias de vida}

Em juvenis com média de $8 \mathrm{~mm}$ de CT, houve crescimento geral dos ossos em espessura, por deposição de fosfato de cálcio e por alongamento das peças (Fig. 7). Nesta idade, o quadrado aparece reabsorvendo o tecido cartilaginoso e depositando o material ósseo. O supra-etmóide aumentou de tamanho e o metapterigóideide está, praticamente, no mesmo estágio (Fig. 7). O pré-opérculo posiciona-se entre o opérculo e a face lateral do hiomandibular e conecta, ventralmente, o simplético.

O supra-occipital desenvolve em sua porção central, uma estrutura como fosse uma pequena coroa, a qual chamamos coronet. Os frontais desenvolveram-se, aumentando suas projeções ósseas sobre o teto cranial, com cristas que convergem, sobre os olhos, a partir do supra-etmóide (Fig. 7) até a altura do esfenótico.

Observou-se um espécime com três radiais proximais na nadadeira anal sem qualquer fusão, enquanto que na nadadeira dorsal, onde encontrávamos fusão entre o $15^{\circ}$ e $16^{\circ}$, houve cisão entre os mesmos com completa separação, ficando o $15^{\circ}$ radial livre (Fig. 8).

\section{Dez dias de vida}

Em juvenis com média de $9 \mathrm{~mm}$ de CT, ocorre reabsorção dos elementos cartilaginosos nos radiais proximais das nadadeiras dorsal (Fig. 9) e anal. Em um espécime, observou-se fusão entre os radiais proximais $10^{\circ}$ e $11^{\circ}$ e $15^{\circ}$ e $16^{\circ}$ da nadadeira dorsal.

O desenvolvimento acentuou-se no frontal, com suas projeções ósseas tornando-se mais evidentes, assim como o coronet do supra-occipital.

As demais estruturas permanecem semelhantes à fase anterior.

\section{Dezesseis dias de vida}

Em juvenis com uma média de $11,2 \mathrm{~mm}$ de $\mathrm{CT}$, houve um grande e geral incremento em todos os ossos. O quadrado, em sua face dorsal, permanece cartilaginoso e o endopterigóide, que cresce sobre esta face (Fig. 10), quase toca o metapterigóide em sua porção anterior. Entre estes ossos, aparecem os suborbitais, em número de dois nesta fase, os quais são ossos dérmicos, laminares e de forma ovalada. Sobre o ectopterigóide, começa a ossificar o palatino. O vômer, osso dérmico, aparece e começa ossificar a partir de sua porção anterior.

O pré-opérculo e o opérculo estão bem visíveis. O primeiro emite projeções sobre o hiomandibular e o simplético, enquanto que o último tem suas cristas (Fig. 11 ), como no frontal, mais evidenciadas. O interopérculo aparece como uma fina ossificação dermal na altura da porção anterior do basi-hial (Fig. 14). O pré-frontal ossificou e o etmóide lateral ainda está cartilaginoso. O supra-etmóide, osso dérmico, emite projeções que envolvem a placa etmóide cartilaginosa; esta começa a ser reabsorvida (Fig. 12). O arco ectemóide permanece cartilaginoso. Nesta região é visível a narina que se comunica com a cápsula nasal (Figs 12,15).

O simplético ossificou e mantém um vestígio de cartilagem na região anterior, que permanecerá no adulto. O hiomandibular, em ossificação, apresenta sua região inferior cartilaginosa. Ligado a este osso está o inter-hial, primeiro 
elemento totalmente ósseo do arco hióide. Seguem-se os cerato-hiais com a região bulbar ainda cartilaginosa e os hipo-hiais não totalmente ossificados. O basi-hial começa a reabsorver cartilagem e depositar fosfato de cálcio (Fig. 13). O pequeno uro-hial, em forma de colher, está mais encorpado (Fig. 11).

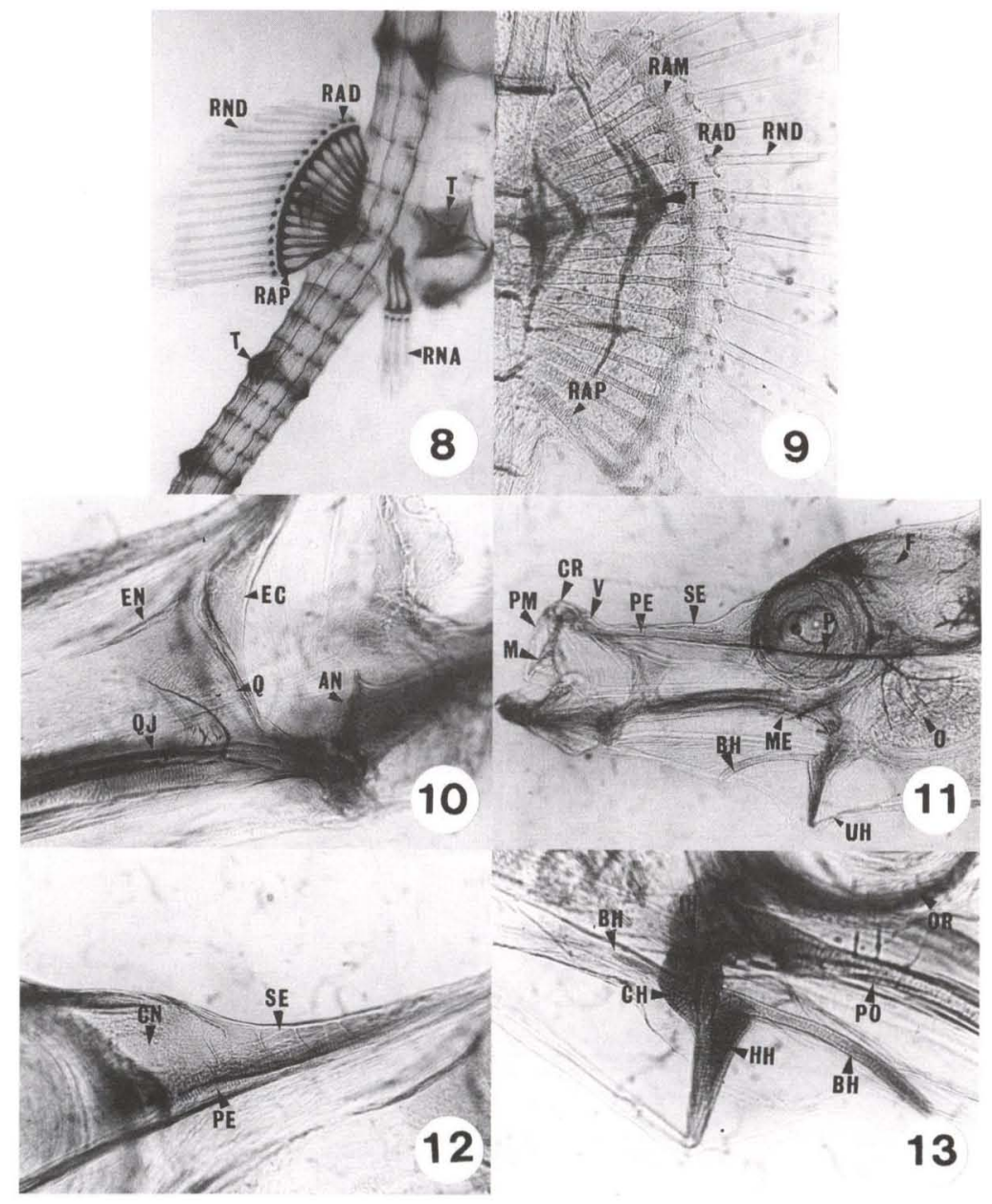

Figs 8-13. Hippocampus reidi, desenvolvimento de 7 até 16 dias de vida. (8) Juvenil com sete dias de vida; (9) nadadeira dorsal com sete dias se vida; (10) região oromandibular com sete dias de vida; (11) sincrânio com 16 dias de vida; (12) região olfatória com 16 dias de vida; (13) região hióide com 16 dias de vida. (AN) Angular, $(\mathrm{BH})$ basi-hial, $(\mathrm{CH})$ cerato-hial, $(\mathrm{CN})$ cápsula nasal, (CR) cartilagem rostral, $(E C)$ ectopterigóide, (EN) endopterigóide, $(H H)$ hipo-hial, $(M)$ maxilar, (ME) metapterigóide, (OR) órbita, $(\mathrm{PE})$ placa etmóide, (PM) pré-maxilar, ( $P O)$ préopérculo, $(Q)$ quadrado, (QJ) quadradojugal, (RAD) radial distal, (RAM) radial mesial, (RAP) radial proximal, (RAP) radial proximal, (RNA) raio da nadadeira anal, (RND) raio da nadadeira dorsal, (SE) supra-etmóide, (T) tubérculo, (UH) uro-hial, (V) vômer. 
Ocorreu fraca deposição de minerais nos radiais proximais dorsais. Observou-se um espécime com 15 radiais proximais dorsais e sem fusão. Sobre a nadadeira dorsal ocorrem três tubérculos. Nesta fase, o pedicelo óptico e o processo pós-orbital são bem visíveis na parte posterior ao olho. O esfenótico e o pós-temporal permanecem cartilaginosos. O pterótico ossificou em grande parte. O exoccipital e o epiótico ossificaram (Fig. 14).

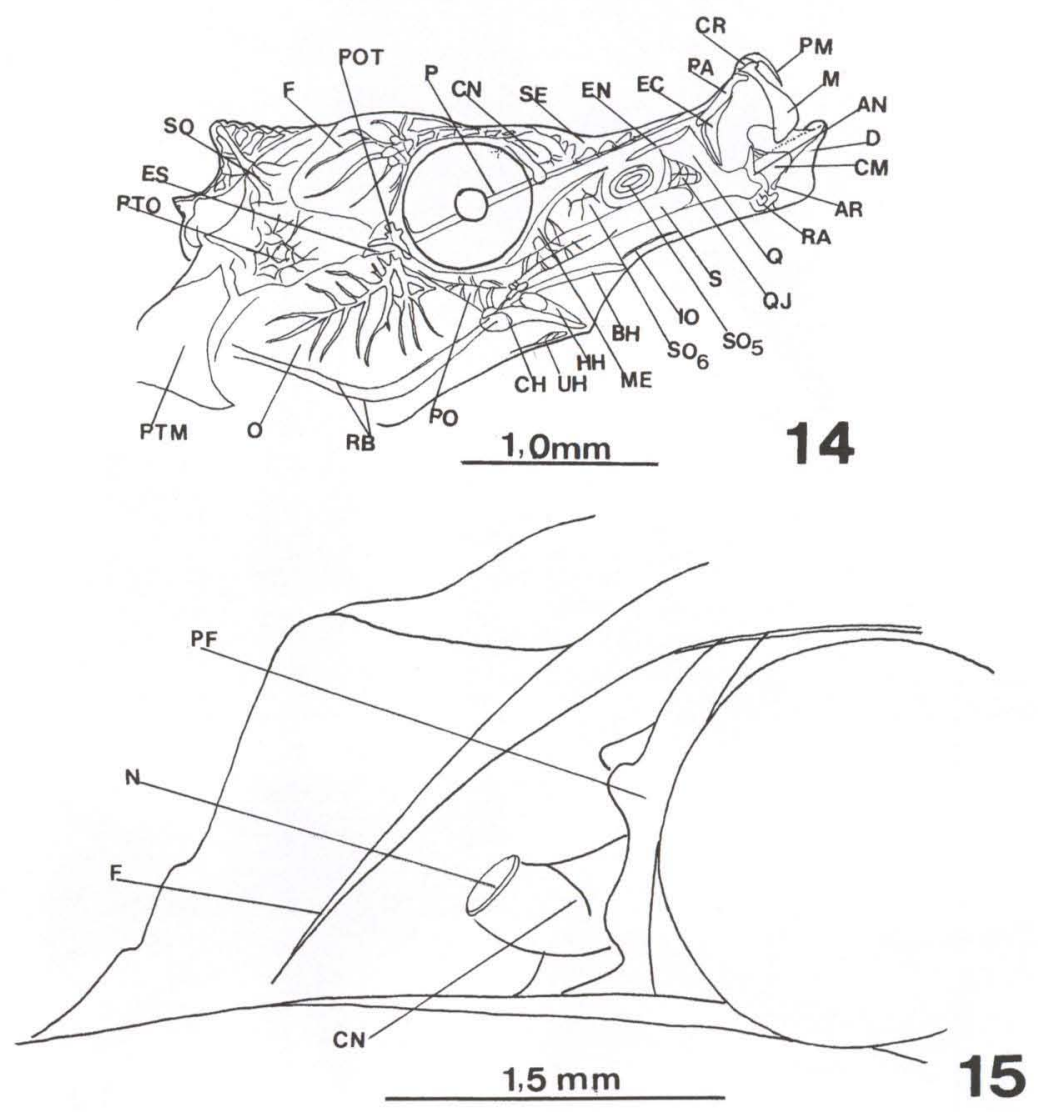

Figs 14-15. Hippocampus reidi. (14) Sincrânio juvenil com 16 dias de vida; (15) região olfatória de adulto. (AN) angular, (AR) articular, $(B H)$ basi-hial, $(\mathrm{CH})$ cerato-hial, $(\mathrm{CM})$ cartilagem de Meckel, (CN) cápsula nasal, (CR) cartilagem rostral, (D) dentário, (EC) ectopterigóide, (EN) endopterigóide, $(E S)$ esfenótico, $(F)$ frontal, $(F)$ frontal, $(H H)$ hipo-hial, (IO) interopérculo, $(M)$ maxilar, (ME) metapterigóide, $(\mathrm{N})$ narina, $(\mathrm{O})$ opérculo, $(\mathrm{P})$ parasfenóide, $(\mathrm{PA})$ palatino, $(\mathrm{PF})$ pré-frontal, (PM) pré-maxilar, (PO) pré-opérculo, (POT) pedicelo óptico, (PTM) pós-temporal, (PTO) pterótico, $(\mathrm{Q})$ quadrado, $(\mathrm{QJ})$ quadradojugal, (RA) retroarticular, $(\mathrm{RB})$ raios branquiostegais, (S) simplético, (SE) supra-etmóide, (SO) supra-occipital, ( $\left.\mathrm{SO}_{5}\right)$ suborbital $5,\left(\mathrm{SO}_{6}\right)$ suborbital 6, (UH) uro-hial. 


\section{Vinte dias de vida}

Em juvenis com média de $11,1 \mathrm{~mm}$ de $\mathrm{CT}$, aparecem os primeiros sinais de ossificação nos arcos branquiais. A placa etmóide permanece cartilaginosa; abaixo dela segue um fino e longo osso que vai até o vômer e está fundido a ele, é o mesetmóide. Os radiais proximais dorsais estão ossificando. Os suborbitais, entre o metapterigóide e o quadrado, aumentaram de tamanho, quase tocando os limites superiores deste ossos e do endopterigóide. $\mathrm{O}$ interopérculo atinge seu local definitivo, fortemente conectado à porção anterior do quadradojugal (Fig. 18).

As demais estruturas não apresentaram mudanças significativas.

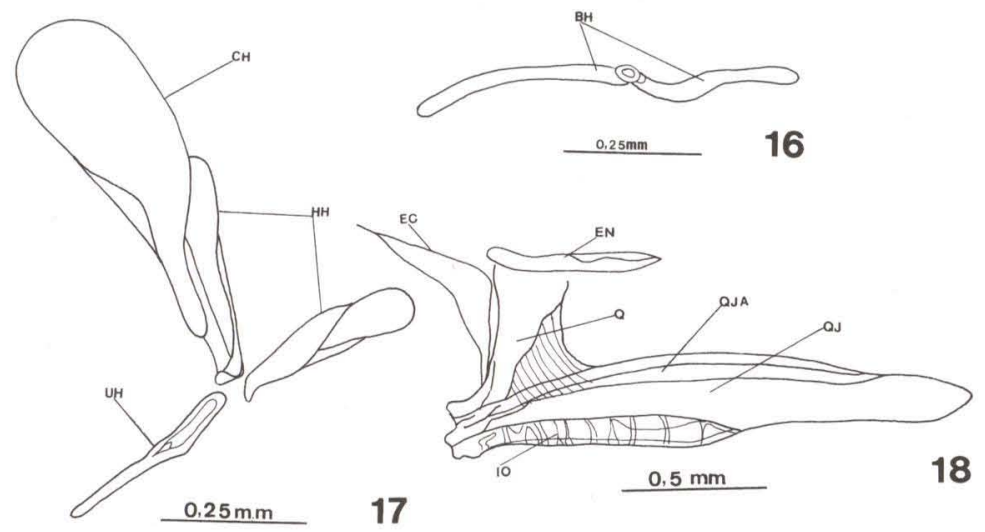

Figs 16-18. Hippocampus reidi. (16-17) Arco hióide com 30 dias de vida. (18) Quadradojugal e ossos associados com 30 dias de vida. $(\mathrm{BH})$ Basi-hial, $(\mathrm{CH})$ cerato-hial, (EC) ectopterigóide, (EN) endopterigóide, $(\mathrm{HH})$ hipo-hial, $(\mathrm{IO})$ interopérculo, $(\mathrm{Q})$ quadrado, $(\mathrm{QJ})$ quadradojugal, (QJA) aba do quadradojugal, (UH) uro-hial.

\section{Vinte e cinco dias de vida}

Em juvenis com média de $14 \mathrm{~mm}$ de CT, três suborbitais estão completamente fechados entre o metapterigóide e quadrado, sobre o quadradojugal. Não observamos grandes modificações desde a última análise ( $20 \mathrm{dv})$.

Todos os radiais distais e mesiais permanecem cartilaginosos, enquanto os proximais ossificam. Os radiais da nadadeira peitoral estão cartilaginosos, o coracóide e a escápula também. A placa etmóide está ossificando.

\section{Trinta dias de vida}

Em juvenis com média de $16,0 \mathrm{~mm}$ de CT, ao desmembramento do focinho, as maxilas exibem seus componentes bastante desenvolvidos. Na maxila superior estão, bem delimitados, os pré-maxilar, maxilar, cartilagem rostral, palatinos, vômer e, fusionado a ele, o mesetmóide (Fig. 21). Na maxila inferior, o dentário, cartilagem de Meckel, angular, retroarticular e o articular (Fig. 20).

$\mathrm{O}$ arco hióide não ossificou completamente; permanecem cartilaginosos as faces anteriores do hipo-hial e basi-hial e o bulbo do cerato-hial (Figs 16, 17). O quadrado tem sua face dorsal ainda cartilaginosa, enquanto que o endopterigóide, 

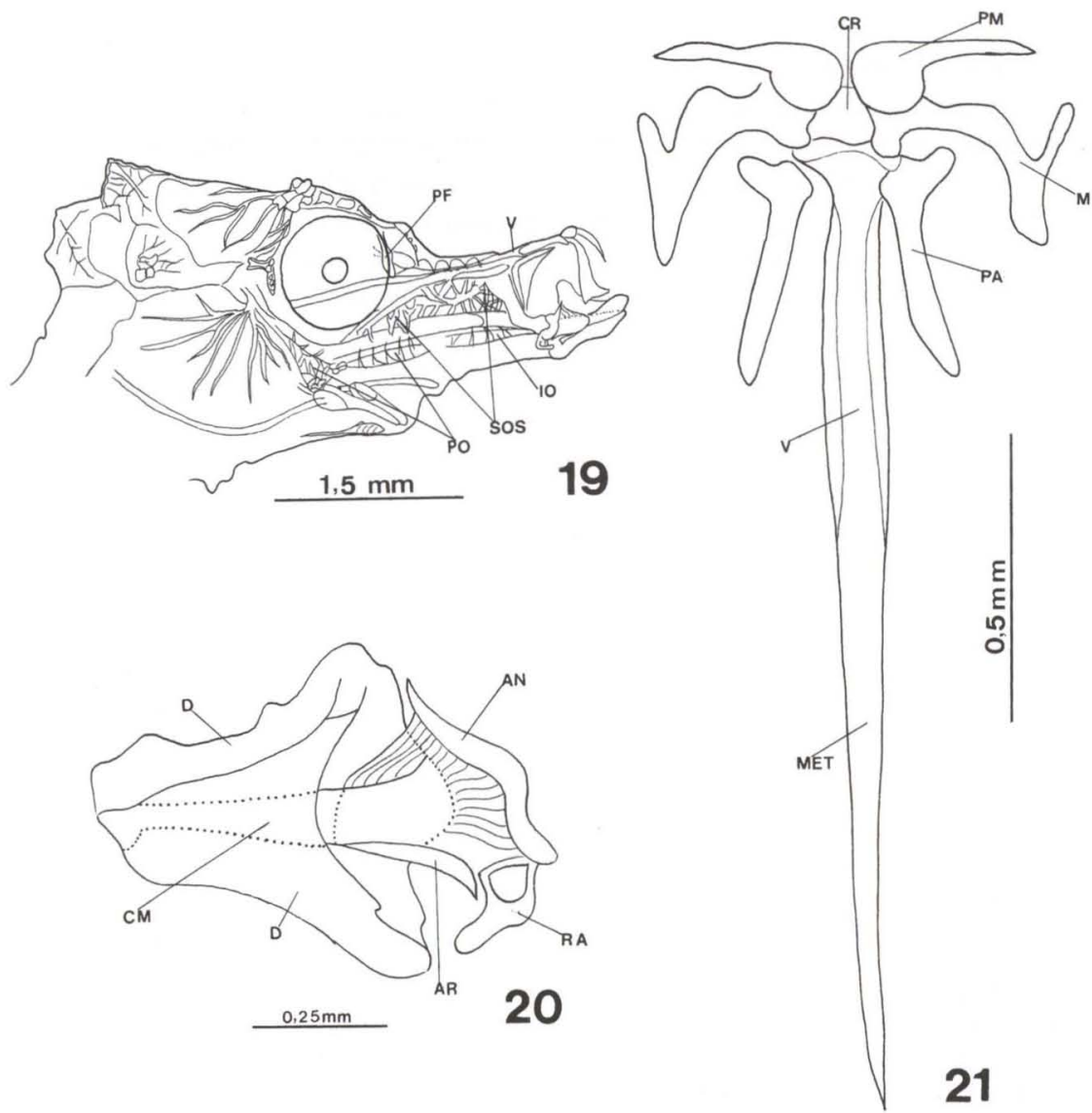

Figs 19-21. Hippocampus reidi. (19) Sincrânio com 30 dias de vida; (20-21) maxilas e ossos associados com 30 dias de vida. (AN) Angular, (AR) articular, (CM) cartilagem de Meckel, (CR) cartilagem rostral, (D) dentário, (IO) interopérculo, (M) maxilar, (MET) mesetmóide, (PA) palatino, (PF) pré-frontal, (PM) pré-maxilar, (PO) pré-opérculo, (RA) retroarticular, (SOS) suborbitais, (V) vômer.

sobre esta mesma face, cresce ossificado (Fig. 18). A porção basal do metapterigóide envolve o simplético, colocando-se sobre ele. O quadrado está colocado sobre a porção anterior do quadradojugal e fusionado a este osso (Fig. 18). Os suborbitais, em número de três, repousam sobre o quadradojugal, suportados por uma aba (Fig. 18) que ocorre em toda extensão do osso. Os suborbitais estão colocados na face dorsal desta aba, enquanto que ventralmente e paralelo ao corpo do quadradojugal, encaixa o simplético. Em sua região anterior, lateralmente, o quadradojugal abriga o inter-opérculo (Fig. 18) e em sua parte distal une-se ao pré-opérculo.

A região olfatória, com exceção do arco ectemóide, ossificou. O pré-frontal (Fig. 19) está fortemente conectado ao etmóide lateral. Este último, quase toca ventralmente a placa etmóide que completou sua ossificação. 
Os radiais proximais das nadadeiras dorsal e anal ainda não estão completamente ossificados e os demais elementos de sustentação continuam cartilaginosos. O cleitro emite um tubérculo sobre a nadadeira peitoral e inicia ossificação do coracóide e escápula. Os arcos branquiais ossificaram. O esfenótico, pteróico, pró-ótico, processo pós-orbital, e o pós-temporal ossificaram (Fig. 22).Ventralmente, no neurocrânio, aumentaram de tamanho o paresfenóide e os forames metótico e trigeminal (Figs 23, 24). O pedicelo óptico é muito evidente (Fig. 25).

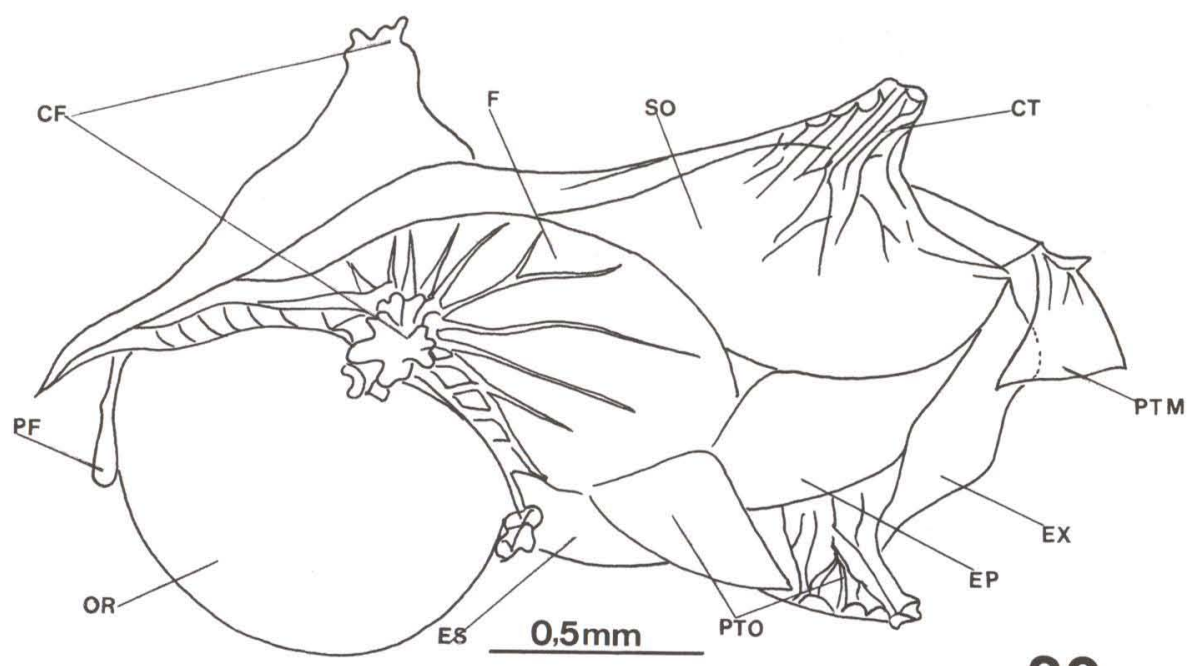

22

Fig. 22. Hippocampus reidi, neurocrânio látero-dorsal com 30 dias de vida. (CF) Cristas do frontal, (F) frontal, (SO) supra-occipital, (CT) coronet, (PTM) pós-temporal, (EX) exoccipital, (EP) epiótico, (PTO) pterótico, (ES) esfenótico, (OR) órbita, (PF) pré-frontal.

\section{Trinta e sete dias de vida}

Em juvenis com média de $16,7 \mathrm{~mm}$ de $\mathrm{CT}$, os ossos estão ainda mais evidentes, não só pelo tamanho, mas pela riqueza de detalhes em cristas e ranhuras. O interopérculo é fortemente fixado ao quadradojugal; este último tem sua porção anterior fusionada ao quadrado, que se articula com o angular (Figs 26, 27).O hiomandibular completou ossificação.

Os radiais proximais da dorsal e anal ainda não ossificaram completamente. Os radiais distais e mesiais permanecem cartilaginosos e irão manter-se assim no adulto. A coluna vertebral apresenta-se robusta, com largas vértebras que vão diminuindo de tamanho até chegar na placa hipural (Fig. 28). Tanto as vértebras pré-caudais (Fig. 29) como as caudais (Fig. 30) apresentam processo transverso. Os radiais peitorais, o coracóide e a escápula estão reabsorvendo tecido cartilaginoso e no adulto confirmam-se estas ossificações (Fig. 31).

Sobre as faces dorsais do metapterigóide e endopterigóide, frente às órbitas, estão formando-se os demais suborbitais que no adulto definirão-se em número de 
três, num total de seis suborbitais. O primeiro suborbital é o maior em comprimento e altura e está colocado sobre os outros dois; concluindo a formação da série suborbitais com o $\mathrm{SO}_{1}$ ou lacrimal, assentando imediatamente sobre o $\mathrm{SO}_{2}$ e $\mathrm{SO}_{3}$ (Fig. 32). Os suborbitais 4, 5 e 6 ficaram colocados abaixo destes, entre o metapterigóide e o endopterigóide (Figs 32, 33, 34, 35).

O neurocrânio não apresenta modificações significativas em relação aos 30 dv. Para um melhor acompanhamento de sua evolução ver Figs 36, 37, 38, 39.
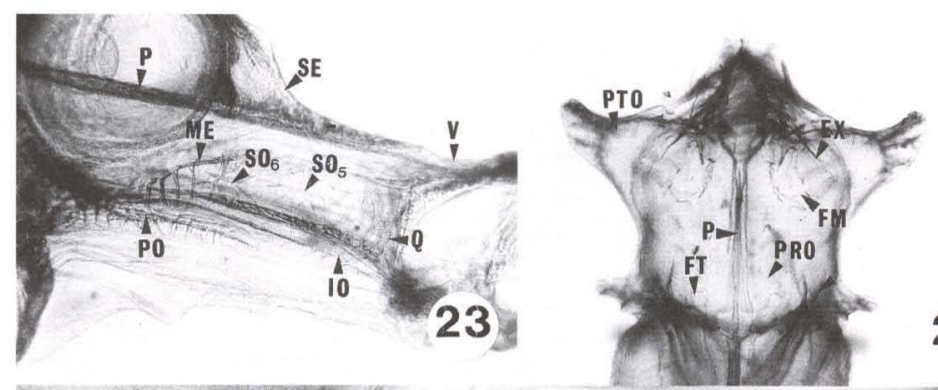

24

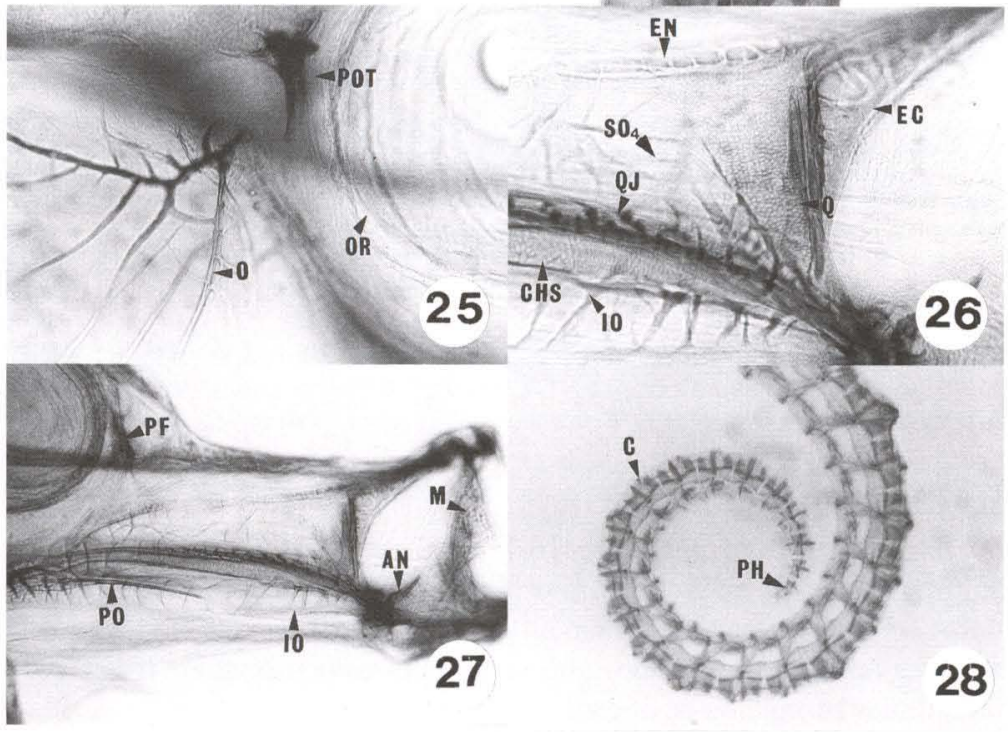

Figs 23-28. Hippocampus reidi, desenvolvimento de 30 até 37 dias de vida. (23) Região oromandibular com 30 dias de vida; (24) neurocrânio ventral com 30 dias de vida; (25) região pós-orbital com 30 dias de vida; (26-27) região oromandibular com 37 dias de vida; (28) cauda com 37 dias de vida. (AN) Angular, (C) cauda, (CHS) cartilagem hiosimplética, (EC) ectopterigóide, (EN) endopterigóide, (EX) exoccipital, (FM) forame metótico, (FT) forame trigeminal, (IO) interopérculo, (M) maxilar, (ME) mesetmóide, (O) opérculo, $(\mathrm{OR})$ órbita, $(\mathrm{P})$ paresfenóide, (PF) pré-frontal, (PH) placa hipural, (PO) pré-opérculo, (POT) pedicelo óptico, (PRO) proótico, (PTO) pterótico, (Q) quadrado, (QJ) quadradojugal, (SE) supraetmóide, $\left(\mathrm{SO}_{4}\right)$ suborbital 4 , $\left(\mathrm{SO}_{5}\right)$ suborbital $5,\left(\mathrm{SO}_{6}\right)$ suborbital 6, $(\mathrm{V})$ vômer. 


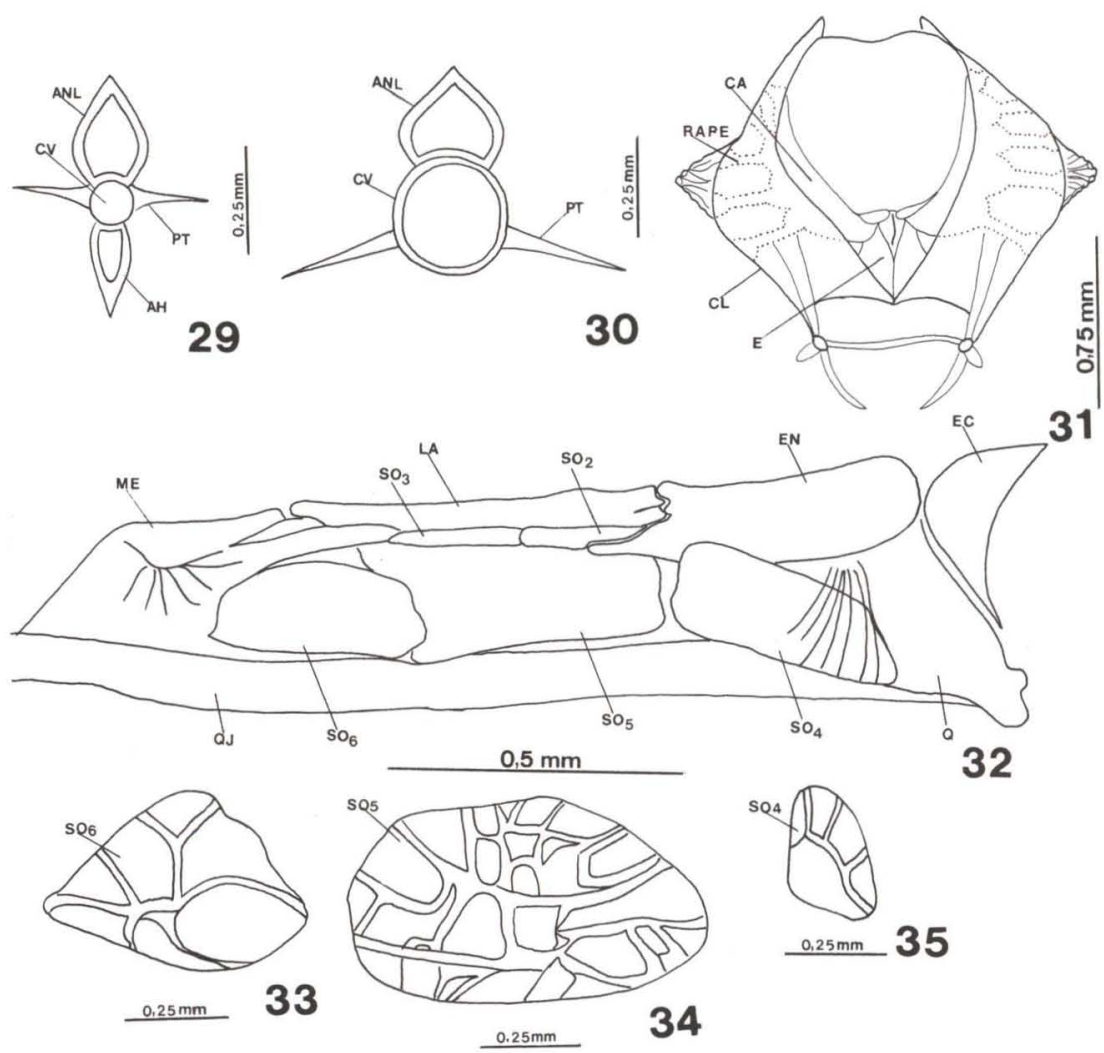

Figs 29-35. Hippocampus reidi. (29-30) Vértebras com 30 dias de vida: (29) vértebra caudal; (30) Vértebra pré-caudal; (31) cintura peitoral com 30 dias de vida; (32) séries suborbitais e pterigóides em adulto; (33-35) suborbitais com 30 dias de vida. (AH) Arco hemal, (ANL) arco neural, $(C A)$ coracóide, (CL) cleitro, (CV) entro vertebral, $(E)$ escápula, $(E C)$ ectopterigóide, (EN) endopterigóide, (LA) lacrimal, (ME) metapterigóide, (PT) processo transverso, (QJ) quadradojugal, (RAPE) radiais peitorais, $\left(\mathrm{SO}_{2-6}\right)$ suborbital $2,3,4,5,6$, respectivamente.

\section{DISCUSSÃO}

$\mathrm{O}$ embrião de $H$. reidi exibe caracteres muito semelhantes aos descritos por AZZARELlo (1990) para Hippocampus zosterae Jordan \& Gilbert, 1882 e Syngnathus scovelli (Evermann \& Kendall), outras duas espécies pertencentes à família Syngnathidae. Após o nascimento, durante o crescimento e a ossificação, começam a aparecer diferenças morfológicas entre as espécies, inclusive entre as espécies de Hippocampus. Para AzZARELlo (1990), a placa etmóide não ossifica em H. zosterae e S. scovelli; em H. reidi a referida placa sofre ossificação. O palatino em $H$. zosterae não ossifica; em S. scovelli (AZZARELLO 1990) e H. reidi ocorre ossificação, mantendo-se apenas alguns pequenos pontos cartilaginosos, sugerindo fusão entre o palatino e autopalatino, como na maioria dos teleósteos e alguns teleósteos primitivos (JoLLIE 1975). 

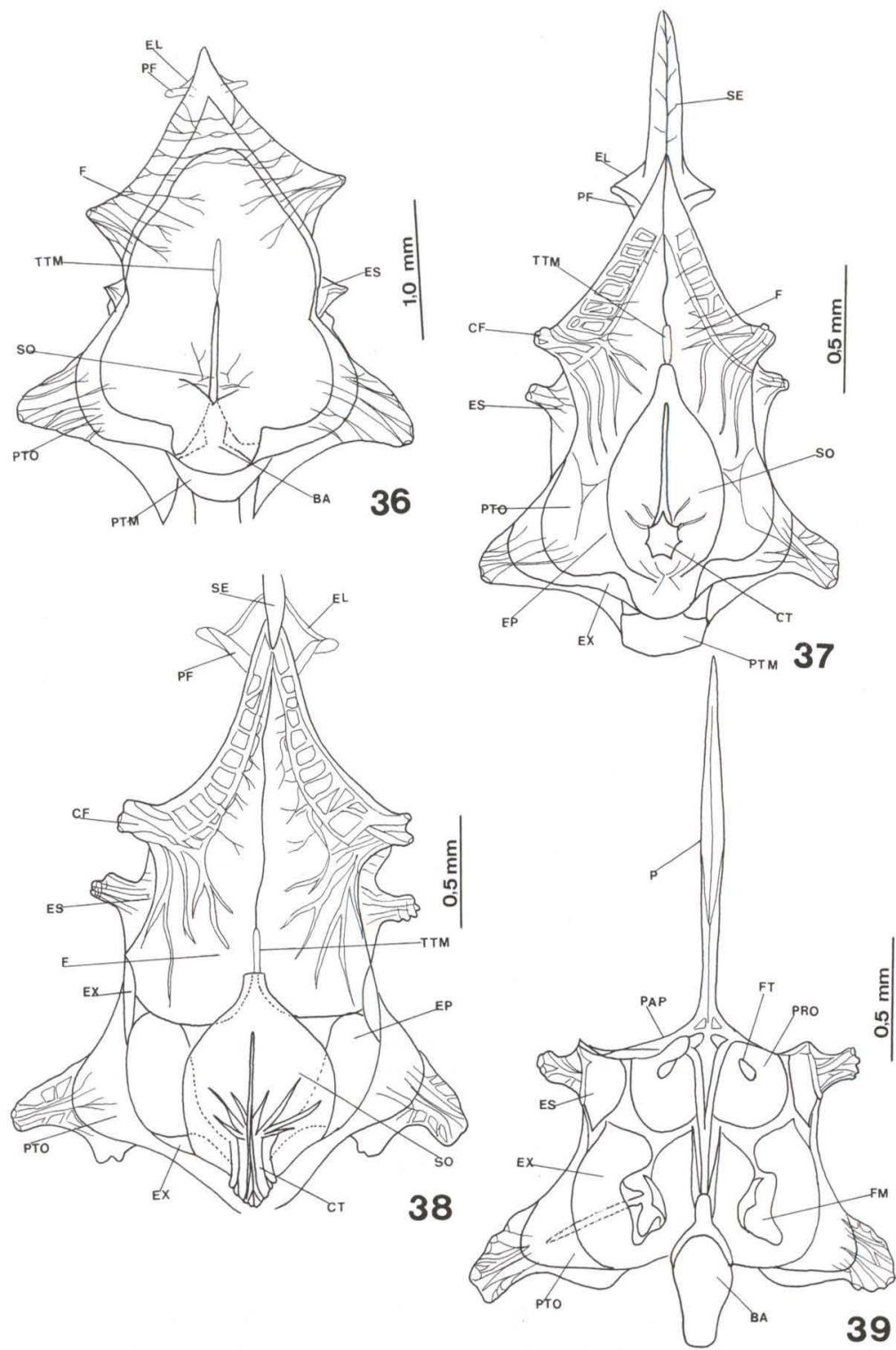

Figs 36-39. Hippocampus reidi, desenvolvimento do neurocrânio de um até 30 dias de vida. (36) Um dia de vida, dorsal; (37) 16 dias de vida, dorsal; (38) 30 dias de vida, dorsal; (39) 30 dias de vida, ventral. (BA) Basioccipital, (CF) cristas do frontal, (CT) coronet, (EL) etmóide lateral, (EP) epiótico, (ES) esfenótico, (EX) exoccipital, (F) frontal, (FM) forame metótico, (FT) forame trigeminal, (P) paresfenóide, (PF) pré-frontal, (PRO) proótico, (PTM) pós-temporal, (PTO) pterótico, (SE) supra-etmóide, (SO) supraoccipital, (TTM) taenia tectum medialis, (PAP) processo ascendente do paresfenóide. 
As maxilas em $H$. reidi não apresentam dentes, nem projeções ósseas funcionando como dentes, como no peixe cachimbo Choerichthys sculptus (Günther, 1870), descrito por DAWSON \& FRITZSCHE (1975).

Nos Syngnathidae, segundo AzZARELLo (1990), foi identificado o articular somente em S. scovelli; para este autor, H. zosterae não possui articular. Em H. reidi, o articular está bem delimitado na face póstero -lateral da cartilagem de Meckel, em continuidade com o angular, e como em $S$. scovelli, nenhum destes ossos estão fundidos (AZZARELLO 1990).

KADAM (1957) chama de cartilagem hiosimplética a união do simplético e hiomandibular em uma peça única desde o período embrionário, como visto em Hippocampus ramulosos Leach, 1814, embora sejam tratados como estruturas cartilaginosas ou ósseas independentes por AzZARELLo (1990). Observamos ser o simplético e o hiomandibular uma peça única, desde o período embrionário e referimo-nos a um ou outro, como partes de uma mesma estrutura para uma descrição mais detalhada. GREGORY (1959) considera o simplético como parte inferior do hiomandibular.

O arco hióide em $H$. reidi está de acordo com AzZarello (1990), que descreve para $H$. zosterae, os cerato-hiais, hipo-hiais e inter-hiais como estruturas pares e o basi-hial, impar; todas estas estruturas ossificam.

Nos Singnatídeos analisados por AzZARELlo (1990), o mesetmóide não estava presente. Para $H$. reidi, verificou-se um remanescente mesetmóide fundido ao vômer, ventral à porção anterior do paresfenóide, como em Fistularia sp., outro Syngnathiformes (GREGORY 1959).

Os ossos da série suborbital em $H$. reidi são em número de seis, o lacrimal e outros cinco suborbitais. Segundo AzZARELLo (1989, 1990), em H. zosterae foi encontrado somente o lacrimal e em $S$. scovelli apareceram dois, o lacrimal e um suborbital (não nomeado pela autora), nos dois casos, colocados entre o metapterigóide e o quadrado. Nesta mesma posição, situam-se os suborbitais 4, 5 e 6 de $H$. reidi. O lacrimal coloca-se sobre os suborbitais 2 e 3; estes últimos posicionam-se ao longo das faces dorsais do metapterigóide e endopterigóide. O lacrimal é mais largo e aproximadamente duas vezes o comprimento dos suborbitais 2 e 3 . Segundo GREGORY (1959), em Centriscus scutatus Linnaeus, 1758 (Centriscidae), o lacrimal posiciona-se sobre o metapterigóide. A constatação de três suborbitais entre o metapterigóide e quadrado de $H$. reidi, só foi possível após a remoção dos mesmos do focinho do animal (aos 30 dias de vida), pois o exame sem a remoção deixava ver, apenas, dois suborbitais. $\mathrm{O} \mathrm{SO}_{4}$ apresentava-se mascarado na junção do quadradojugal com o quadrado. A ausência dos demais suborbitais em H. zosterae, que apresentou somente o lacrimal, pode ser atribuída a perdas ontogenéticas, devido a seu reduzido tamanho (este cavalo marinho possui $40 \mathrm{~mm}$ de CT médio, no adulto, contra $170 \mathrm{~mm}$ CT médio no adulto de $H$. reidi); ou simplesmente, pela não remoção destes ossos do focinho.

O quadradojugal é tido como um caráter primitivo, estando presente em crossopterígios e actinopterígios inferiores (WESTOLL 1937; JARVIK 1947). PATTERSON (1973) sugere que, homologamente, a porção posterior do quadrado possa representar o quadradojugal. AzZARELlo (1990) afirma que esta estrutura 
desenvolve-se a partir de um rudimento parcial ou completamente independente do quadrado em alguns teleósteos, inclusive em H. zosterae e $S$. Scovelli. Hippocampus reidi exibe o crescimento do quadradojugal em íntimo contato com o quadrado, porém, como uma estrutura parcialmente independente. Durante o período juvenil, ele cresce, inicialmente, sobre a face dorsal do simplético e posteriormente, posiciona-se lateralmente ao longo da face interna do simplético, envolvendo-o parcialmente, e apresentando-se fusionado ao quadrado, somente em sua região anterior. AZZARELLO (1990) observa em $H$. zosterae e $S$. scovelli, o quadradojugal crescendo ao longo da face dorsal do simplético e refere-se à conecção do quadrado e quadradojugal como "íntimo contato", não assumindo o termo fusão.

Os singnatídeos possuem cintura peitoral simples composta por cleitro, coracóide e escápula (GREGORY 1959). A cintura pélvica é inexistente. Estas estruturas são confirmadas para $H$. zosterae, $S$. scovelli (AZZARELlo 1990) e $H$. reidi. A ossificação da cintura peitoral ocorre para $S$. scovelli e $H$. reidi, enquanto que para $H$. zosterae somente o cleitro ossifica. Para Fistularia sp., segundo GREGORY (1959), ocorre a ossificação da cintura peitoral. Os radiais da nadadeira peitoral ossificam em todos os Syngnathiformes citados. Já os raios das nadadeiras dorsal e anal ossificam em $H$. zosterae e os raios da peitoral, não. Enquanto que em $S$. scovelli, ossificam os raios das nadadeiras dorsal e peitoral, mas não a anal (AzZARELlo 1990). Para H. reidi, os raios das nadadeiras dorsal, peitoral e anal ossificam, os radiais mesiais e distais não; somente os radiais proximais ossificam.

O processo pós-orbital de $H$. reidi, que articula-se ao processo ascendente do paresfenóide, ossifica como em $S$. scovelli; já em H. zosterae, segundo AZZARELLO (1990), tal estrutura não ossifica. Os pré-frontais, em $H$. reidi, apresentam-se fundidos aos etmóides laterais e ossificam. Para H. zosterae (AzZARELlo 1990), são usados os termos pré-frontais, etmóides laterais e ectemóides como sinônimos de uma mesma estrutura e esta não ossifica.

A formação do crânio é bastante semelhante entre H. zosterae, S. scovelli (AZZARELlo 1990) e H. reidi, ambos apresentando as mesmas estruturas ósseas. Porém, de acordo com Gill (1905), H. ramulosos apresenta o osso parietal, inexistente nas espécies acima citadas, e com localização coincidente com o epiótico destas. As demais estruturas óssea do crânio de $H$. reidi estão de acordo com as descrições feitas para Hippocampus spp. (GILl 1905; KADAM 1957; AZZARELLO 1990).

AGRADECIMENTOS. Nossos mais sinceros agradecimentos ao Dr. Luiz Roberto Malabarba, à Dra Zilda Margarete $\mathrm{S}$. de Lucena e à Dra Clarice B. Fialho pela leitura crítica do manuscrito e demais sugestões na composição do trabalho. À Profa. Leda Francisca Armani Jardim pelas sugestões nas análises osteológicas e à CAPES pela bolsa mestrado.

\section{REFERÊNCIAS BIBLIOGRÁFICAS}

AzZArelLo, M.Y. 1989. The pterygoid series in Hippocampus zosterae and Syngnathus scovelli. Copeia 3: 621-628.

1990. A comparative study of the developmental osteology of Syngnathus scovelli and Hippocampus zosterae (Pisces, Syngnathidae) and it's phylogenetic implications. Evol. Monogr. 12: 1-90. 
BRownELL, C.L. 1980a. Water quality requirements for first-feeding in marine fish larvae. I. Ammonia, nitrite and nitrate. Jour. Exp. Mar. Biol. Ecol. 44: 269-283.

- 1980b. Water quality requirements for first-feeding in marine fish larvae. II. pH, oxigen, and carbon dioxide. Jour. Exp. Mar. Biol. Ecol. 44: 285-298.

Dawson, C.E. \& R.A. FritZSCHE. 1975. Odontoid processes in pipefish jaws. Nature 257: 2.

GiLl, T. 1905. The life history of the sea horses (Hippocampids). Proc. U.S. Nat. Mus. 28 (1408): 805-814.

GREGORY, W.K. 1959. Fish Skulls. A study of the evolution of natural mechanisms. New York, Noble Offset Printers Inc., 481p.

JARVIK, E. 1947. Notes on the pit -lines and dermal bones of the head in Polypterus. Zoologiska Bidrag Fran Uppsala 25: 60-78.

JoLliE, M. 1975. Development of the head skeleton and pectoral girdle in Esox. Jour. Morphol. 147: 61-88.

KaDAM, K.M. 1957. The development of the chondrocranium in the sea-horse, Hippocampus (Lophobranchii). Jour. Linn. Zool. 43: 557-573.

PATtERSON, C. 1973. Interrelationships of holosteans. In: Interrelationship of Fishes. Zool. Jour. Lin. Soc. 53 (Suppl. 1): 233-305.

SiLVEIRA, R.B. 1998a. Cavalos marinhos ganham protetora no Brasil. Época 16: 75.

. 1998b. Projeto Hippocampus. Natureza 9: 21.

1999. Cavalo Marinho - Projeto Hippocampus. Cultivo do Cavalo Marinho em Laboratório. Aquarista Jr. 65: 28-29.

— 2000. Desenvolvimento osteológico de Hippocampus reidi Ginsburg (Pisces, Syngnathiformes, Syngnathidae) em laboratório. I. Período embrionário. Revta. bras. Zool. 17 (2): 505-513.

VINCENT, A.C.J. 1992. Prospects for sex role reversal in teleost fishes. Jour. Zool. 42: 392-399. 1994a. The improbable seahorse. Nat. Geogr. 186 (4): 128-140.

1994b. Seahorse exhibit convencional sex roles in mating competition, despite male pregnancy. Behaviour 128: 135-151.

. 1995. Trade in Seahorses for Traditional Chinese Medicines, Aquarium Fishes and Curios. Traffic Bulletin 15 (3): 125-128.

Vincent, A.C.J; I. Airnesjö \& G. Rosenqvist. 1992. Pipefishes and seahorses: are they all sex role reversed? Trends. Ecol. Evol. 7: 237-241.

Vincent, A.C.J. \& L.M. SAdLer. 1995. Fathful pair bonds in wild seahorses, Hippocampus whitei. Anim. Behav. 50: 1557-1569.

Westoll, T.S. 1937. On the cheeck -bones in teleostome fishes. Jour. Anat. 72: 362-382.

Recebido em 24.II.1999; aceito em 11.V.2000. 